\title{
Hypertensive "Urgency" Is a Harmful Misnomer
}

\author{
Zachary G. Jacobs, MD $\odot$ \\ Division of Hospital Medicine, Oregon Health \& Science University, Portland, OR, USA.
}

$\mathrm{J}$ Gen Intern Med 36(9):2812-3

DOI: $10.1007 / \mathrm{s} 11606-020-06495-6$

(C) Society of General Internal Medicine 2021

$\mathrm{O}$ ne of the most powerful aspects of language is its plasticity. Our lexicon is constantly evolving to reflect societal trends, to reduce stigma and negative bias, and to integrate new information. Even a few years ago, phrases like "WDYT of the latest on-brand tweet from @ POTUS throwing shade on Obamacare?" or "your new selfie on Instagram is lit, hashtag YOLO" would have seemed utter nonsense; yet as of 2020, all of these words are considered an official part of our vocabulary by the Oxford English Dictionary.

As scientists and healthcare providers, we have an even greater obligation to continually modify our language to reflect current knowledge and best practices, as well as to improve patient care. Sometimes, this happens naturally as our understanding of a disease process evolves. Epilepsy was for many years known simply as a "falling sickness" until the pathophysiology of seizures was elucidated. ${ }^{1}$ Syphilis was first called such in 1530 by Italian physician-poet Girolamo Fracastoro, named after the titular character in his epic poem Syphilis sive morbus gallicus; for many years prior to that, the disease was extraordinarily stigmatized, with impacted nations often blaming it on neighboring countries (e.g., the UK called it "the French disease," France referred to it as "the Neapolitan disease," Russia named it "the Polish disease," and so on). ${ }^{2}$ And before the term tuberculosis was coined in 1834 by German physician Johann Lukas Schönlein, the ailment was known by a variety of names ("phthisis," "tabes," "schachepeth"), all roughly translating to consumption due to its association with gradual weight loss. ${ }^{3}$

In other cases, the changes are more intentional. The medical community has deliberately distanced itself from eponymous names for diseases like Wegener's granulomatosis and Reiter's syndrome not only because they are less helpful than designations based on pathophysiology (granulomatosis with polyangiitis, reactive arthritis) but also because of their namesakes' connections to the Nazi party. There have been concerted efforts to make the use of inclusive, patient-centered

Received October 7, 2020

Accepted December 17, 2020

Published online January 8, 2021 terminology more standardized, including "person-first" language which recognizes that patients are distinct from their diseases (e.g., "patient with diabetes" as opposed to "diabetic"). Similarly, pejorative terms like "drug abuse" and "addict" have been abandoned in favor of less stigmatizing language, such as "person who injects drugs" and "substance use disorder." All these changes take conscious effort, collective buyin, and, most importantly, time. But the first step toward any change is recognizing there is a problem.

The idea of a hypertensive crisis was first introduced by Dr. Koch-Weser in 1974, who even at the time recognized that "rapid normalization of blood pressure is unnecessary, often uncomfortable, and sometimes hazardous.", This concept was later operationalized in the third report by the Joint National Committee (JNC 3) on hypertension in $1984 .{ }^{5}$ Both so-called crises are typically defined as having a blood pressure $\geq$ $180 \mathrm{mmHg}$ systolic or $\geq 90 \mathrm{mmHg}$ diastolic, though these numbers are arbitrary. The difference is that, in the case of a hypertensive emergency, patients present with symptoms or signs of acute end-organ damage, while those with hypertensive urgency are asymptomatic.

While hypertensive emergencies are incredibly rare-as few as 1-2 per million hospitalizations according to recent estimates - they are associated with high morbidity and mortality, even in the short term. ${ }^{6}$ Conversely, while hypertensive "urgencies" are common, there is no evidence to suggest short-term deleterious effects without treatment-which is contrary to the prevailing belief at the time JNC 3 was published.

And therein lies the issue. In the last several years, there has been increasing recognition of the problematic nature of the term hypertensive "urgency." While it appears at first glance helpful to dichotomize these seemingly related phenomena in this way, the term "urgency" ends up conferring an undue sense of gravity to a truly nonurgent situation. It encourages providers to treat such patients with rapid reduction in blood pressure despite the fact there is no evidence to support this practice, or to suggest that failing to do so confers any additional short-term risk. In fact, virtually, all the major governing bodies for the management of hypertension agree that rapid reduction of blood pressure in patients with hypertensive "urgency" is not only unnecessary but also potentially harmful. ${ }^{7}$

The fact is there is nothing urgent about hypertensive "urgencies." The term is outdated and incongruent with current guidelines - a harmful misnomer. The risks associated with 
uncontrolled hypertension are undeniable even when asymptomatic, but these accumulate over the course of months, not hours or days or even weeks. However, there are very real short-term risks associated with overtreatment. Rapid reduction of blood pressure among patients with hypertensive "urgency" is not only unnecessary, wasteful, and contrary to current best practice guidelines; it is also unsafe.

There has already been a movement in recent years away from the overly aggressive treatment of hypertensive urgencies; however, until the language we use to describe this condition is also changed, the practice will persist, lagging behind the guidelines. A better term, severe asymptomatic hypertension, has already begun to come into favor. However, a search of PubMed for articles containing the term "hypertensive urgency" shows 63 published so far in 2020.

We can do better. There is plenty of precedent for doing so: throwing shade on outdated terminology is very on-brand for the medical community. We no longer blame neighboring countries for sexually transmitted infections. We denounce eponyms for their associations with hate. We reject pejorative language and avoid defining our patients by the illnesses from which they suffer. In a similar vein, it is time we update the terminology we use for hypertension to reflect current practice guidelines.

Seeing as the term hypertensive "urgency" is still in use nearly fifty years after its inception, it is clear this change will not happen naturally. To that end, I propose that we collectively decide to strike it from our vernacular and use the term severe asymptomatic hypertension in its place. Use it when you write your manuscripts, when you present to your colleagues, and most importantly, when you teach your trainees. Soon enough, just like Wegener's and Reiter's, the idea of a hypertensive "urgency" will be a thing of the past, and our patients will be better off for it. We have recognized the problem; now, it is time for change. This is our chance. Hashtag YOLO.

Corresponding Author: Zachary G. Jacobs, MD; Division of Hospital Medicine, Oregon Health \& Science University, Portland, OR, USA (e-mail: JacobsZ@OHSU.edu).

Conflict of interest: Dr. Jacobs has no conflicts of interest to declare.

\section{REFERENCES}

1. Cule J. The Falling Sickness: A History of Epilepsy from the Greeks to the Beginnings of Modern Neurology. Med Hist. 1973;17(2):214-215.

2. Tampa M, Sarbu I, Matei C, et al. Brief History of Syphilis. J Med Life. 2014;7(1):4-10.

3. Tuberculosis: World TB Day 2020. Centers for Disease Control and Prevention. 12 Dec. 2016, https://www.cdc.gov/tb/worldtbday/history. htm. Accessed September 24, 2020.

4. Koch-Weser J. Hypertensive emergencies. NEJM. 1974;290:211-214

5. The 1984 Report of the Joint National Committee on Detection, Evaluation, and Treatment of High Blood Pressure. Arch Intern Med. 1984; 144: 1045-1057.

6. Astarita A, Covella M, Vallelonga F, et al. Hypertensive emergencies and urgencies in emergency departments: a systematic review and metaanalysis. Hypertens. 2020;38(7): 1203.

7. Whelton PK, Carey RM, Aronow ws, et al. 2017 ACC/AHA/AAPA/ABC/ ACPM/AGS/APhA/ASH/ASPC/NMA/PCNA Guideline for the Prevention, Detection, Evaluation, and Management of High Blood Pressure in Adults: A Report of the American College of Cardiology/American Heart Association Task Force on Clinical Practice Guidelines. Hypertension. 2018;71(6):e13-e115.

Publisher's Note: Springer Nature remains neutral with regard to jurisdictional claims in published maps and institutional affiliations. 